\title{
Possible interactions between fused pyrazole derivative and magnesium ions - NMR experiments and theoretical calculations
}

\author{
Kornelia Czaja, ${ }^{a}$ Jacek Kujawski, ${ }^{* a}$ Urlich Girreser, ${ }^{\text {c Jarosław J. Panek, }}{ }^{\text {d }}$ \\ Marek Doskocz, ${ }^{\mathrm{b}, \mathrm{e}}$ and Marek K. Bernard ${ }^{\mathrm{a}}$ \\ ${ }^{a}$ Department of Organic Chemistry, Faculty of Pharmacy, Poznan University of Medical \\ Sciences, Grunwaldzka 6 str., 60-780 Poznań, Poland \\ ${ }^{b}$ RootInnovation sp. z o.o., Jana Matejki 11 str., 50-333 Wrocław, Poland \\ ${ }^{c}$ Department of Pharmaceutical and Medicinal Chemistry, Pharmaceutical Institute, Christian- \\ Albrechts-University of Kiel, Gutenbergstraße 76, 24118 Kiel, Germany \\ ${ }^{d}$ Theoretical Modeling of Chemical Processes Group, Faculty of Chemistry, University of \\ Wroclaw, F. Joliot-Curie 14 str., 50-383 Wroclaw, Poland \\ ${ }^{e}$ Foundation for Development of Science and Business on Medical and Exact Sciences Area, \\ Legnicka 65 str., 54-206 Wroctaw, Poland \\ E-mail:jacekkuj@ump.edu.pl
}

DOI: $\underline{\text { http://dx.doi.org/10.3998/ark.5550190.p009.427 }}$

\begin{abstract}
The paper verifies our recently described NMR approach for the determination of interaction sites between a heterocyclic ligand and magnesium ions. The method is based on the comparison of chemical shifts of condensed pyrazole derivative before and after the complexation with magnesium salt and is supported by DFT (B3LYP/6-31G(d,p) level of theory, CPCM solvation model, GIAO method) and classical molecular dynamics theoretical calculations.
\end{abstract}

Keywords: Condensed pyrazole, magnesium cation complexation, NMR spectroscopy, DFT calculations

\section{Introduction}

Pyrazoles and their benzanalogues, indazoles, are bioisosters of pyrroles and indoles. The activity spectrum of pyrazole derivatives is quite wide. This class of heterocyclic compounds includes drugs of anti-inflammatory analgesic, antipyretic, antiestrogenic, antibacterial, antiviral, and anticancer activity. Pyrazole derivatives are also useful in the treatment of obesity and CNS disorders including Alzheimer's and Parkinson's disease. ${ }^{1-4}$ Among the anticancer drugs, pyrazole or indazole derivatives like Celecoxib, anthrapyrazoles (piroxantrone, losoxantrone), and Axitinib 
have been found to be effective antineoplastic agents useful in the treatment of breast and prostate cancers, as well as acute leukemia., 5

Magnesium ions, $\mathrm{Mg}^{2+}$, participate in many biochemical processes including these involved in cancerogenesis like proliferation, angiogenesis and apoptosis. ${ }^{7,8}$ The role of magnesium in cancerogenesis is, however, not clearly understood. Magnesium deficiency, hypomagnesaemia, was observed during the treatment of cancer patients with cisplatin or cetuximab alone or with combination with other chemotherapeutics. It was shown that hypomagnesaemia had a beneficial effect in laboratory animals due to inhibition of tumour cell proliferation and neoangiogenesis. On the other hand, this effect was counterbalanced or even outweighted by accelerated cancer invasion and metastatisation. ${ }^{9}$

As mentioned above, hypomagnesaemia was detected in patients with colorectal cancer treated with cisplatin or cetuximab. Cisplatin induced hypomagnesaemia is due to the nephrotoxicity of this drug but the mechanism of cetuximab magnesium deficiency has not been clarified. ${ }^{9}$

Our earlier studies evidenced that some condensed pyrazole derivatives had cytostatic and proapoptotic activity against the HT29 human colorectal cancer cells. ${ }^{10}$ We suggested therein that the mechanism of cytotoxic activity of these compounds could be related to their ability to adhere to DNA. ${ }^{11}$ In addition, we observed DNA cleavage. ${ }^{10,12}$ It is also possible that they can interfere with the cellular $\mathrm{Mg}^{2+}$ ions owing to the presence of pyridinic nitrogen in the pyrazole skeleton. Although the structural difference between the small-molecular pyrazole derivative and proteinaceous antibody cetuximab is huge, the molecular mechanism of hypomagnesaemia induced by both compounds might be similar and may involve complexation of the metal.

The complexation of magnesium ions by many arenes, azoles and other organic molecules has been investigated extensively in the last few years. ${ }^{13-22}$ Investigations on these interactions have been carried out by a variety of analytical methods, including ${ }^{1} \mathrm{H}$ NMR spectroscopy. Noteworthy is the fact that NMR spectroscopy has found its use for the determination of interactions of some ligands with different chemical targets and allows to assess quantitatively these interactions if the equilibrium constants and changes in chemical shifts are taken into account. ${ }^{23,24}$

In our previous paper, we discussed the interactions between an indazole derivative and magnesium ions. ${ }^{25}$ The analysis of chemical shifts before and after the complexation with $\mathrm{Mg}^{2+}$ led to the conclusion that the most susceptible indazole region for the interaction with the metal ion is the NH functionality and position 5 of the ring. In a continuation of our attempts to clarify the anticancer mechanism of the condensed pyrazoles, ${ }^{26,27}$ we present herein our theoretical studies concerning interactions of another fused pyrazole derivative with magnesium cations. We also focused on calculations of the proton chemical shifts of this azole by applying various basis sets and methods in gaseous phase. To give careful consideration to the solvation sphere, we used the conductor-like polarizable continuum (CPCM) solvation model. Moreover, the goal of this work is to improve our protocol for the estimation of interactions between metal ions and small to medium size molecules. Similarly to the previous studies, this approach is very efficient with respect to experimental and measuring times and repeatability of its results under different conditions. ${ }^{24,25}$ 


\section{Results and Discussion}

\section{NMR measurements}

The procedure was tested using the pyrazole derivative obtained by our group, namely 1-methyl6-(4-toluenesulfonyl)pyrazolo[4,3-c]pyrazole (compound 7, Scheme 1), and the results were verified by theoretical calculations. Compound 7 was obtained in a four-step synthesis (Scheme 1). The 4-nitroazole derivative $\mathbf{3}$ was subjected to the vicarious nucleophilic substitution of hydrogen (VNS) and the nitro group was hydrogenated using hydrazine hydrate as a source of hydrogen and palladium as a catalyst to give amine 6. Diazotization of the latter compound proceeded with annulation and afforded the condensed pyrazole derivative $7.25,28$

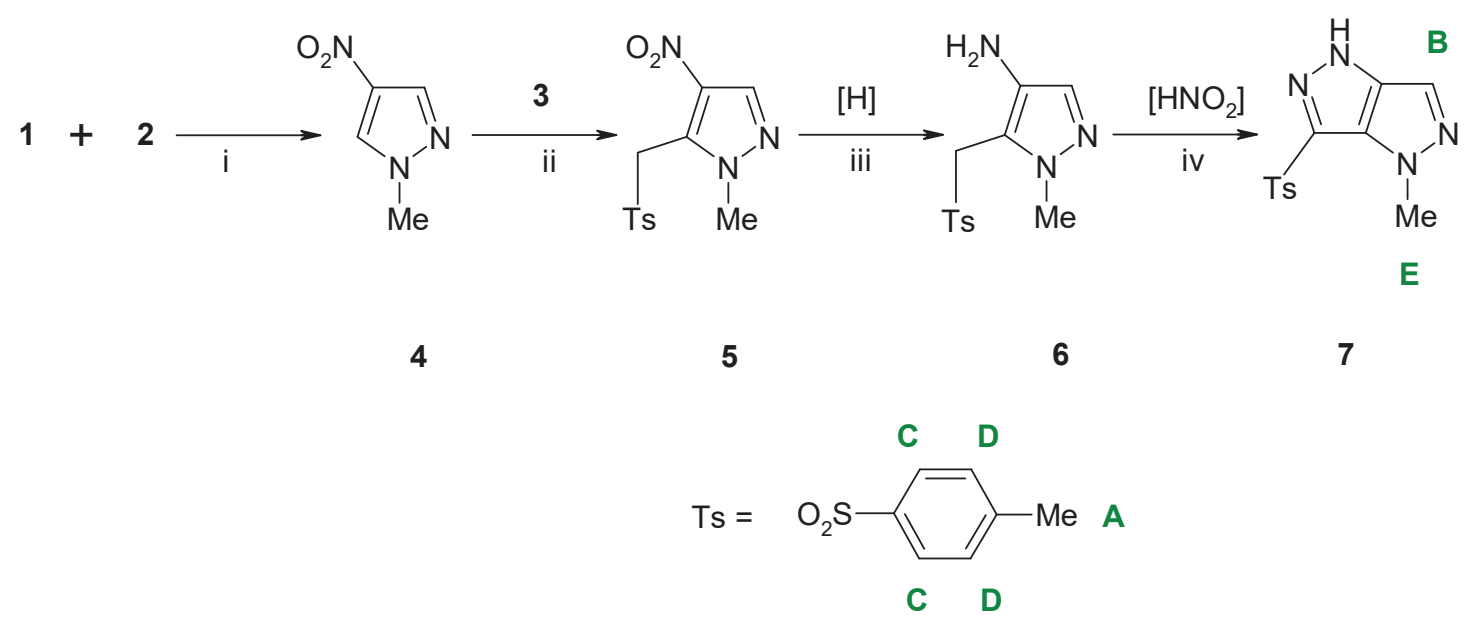

Scheme 1. Synthesis of 1-methyl-6-[(4-methylphenyl)sulfonyl]-1,4-dihydropyrazolo[4,3c]pyrazole (7); 1 - 4-nitro- $1 \mathrm{H}$-pyrazole, $2-\left(\mathrm{CH}_{3}\right)_{2} \mathrm{SO}_{4} ; \mathrm{i}=\mathrm{NaOH} / \mathrm{EtOH}, \mathrm{rt}, 1 \mathrm{~h}$; ii $=\mathrm{DMSO} / \mathrm{KOH}$, rt, $1 \mathrm{~h}, 3-\mathrm{Ts}-\mathrm{CH}_{2}-\mathrm{Cl}$; iii $=\mathrm{H}_{2} \mathrm{~N}-\mathrm{NH}_{2} \mathrm{xH}_{2} \mathrm{O} / \mathrm{Ni}-\mathrm{Ra} / \mathrm{EtOH}$, reflux, $10 \mathrm{~min}$; iv = isopentyl nitrite/AcOH- $\mathrm{SiO}_{2}$ (MAOS, microwave assisted organic synthesis), 5 min.

In order to analyse the interactions between compound 7 and the metal ion, compound 7 was dissolved in DMSO- $d_{6}$ and separately in DMSO- $d_{6}$ with the admixture of $\mathrm{Mg}\left(\mathrm{NO}_{3}\right)_{2} \times 6 \mathrm{H}_{2} \mathrm{O}$. The NMR analysis was based on our previous conclusions drawn from the spectral examination of a complex of dimeric pyrazole with magnesium ions. ${ }^{25}$ The ${ }^{1} \mathrm{H}$ NMR technique, compared to other methods, is fast and cheap, and enables to follow changes in chemical shifts with no need for a time-consuming alternative NMR approach. Herein it must be added that the use of ${ }^{15} \mathrm{~N}$ or ${ }^{17} \mathrm{O}$ NMR techniques would result in serious errors and could not be such informative as there are only few nitrogen and oxygen atoms in the structure of 7 . Very low natural abundance and a relatively large quadrupole moment renders ${ }^{17} \mathrm{O}$ NMR method difficult for routine NMR measurements. The 
first drawback is relevant to ${ }^{15} \mathrm{~N}$ NMR as well. We reasoned then that ${ }^{1} \mathrm{H}$ NMR is the most suitable technique for investigation of such interactions between azoles and metal ions. ${ }^{24,25,29-31}$

The NMR measurements were carried out at three different temperatures, namely at 25, 40 and $60{ }^{\circ} \mathrm{C}$. The shifts in the signal positions refer to the experiments involving separately compound 7 and the same molecule in the presence of magnesium hydrate. In the preceding paper ${ }^{25}$, we concluded that the analysis of the drifts in all proton signals of the molecule indicated that the reference line was not locked during the temperature increase. Therefore, we used the method based on the analysis of relationship between the analyte signals. In order to identify the signals with the highest sensibility to temperature, we focused on the interval changes between the signals. Obviously, the signals that have similar tendencies in the chemical shifts changes will have the same interval between the signals. If one signal drifts downfield and the second stays at the same position or moves less than the first one, then the distance between signals will increase. ${ }^{25}$

In that paper, we also revealed that the change in $\mathrm{pH}$ caused by the addition of magnesium hydrate was insignificant due to the high concentration of DMSO in relation to the analyte. This observation has been confirmed in the present paper as well. The water signal (3.31 ppm) is omitted from the tables due to relatively large drifting that equals to -0.070 and $-0.157 \mathrm{ppm}$ at 40 and 60 ${ }^{\circ} \mathrm{C}$, respectively, or to $0.390,0.365$, and $0.369 \mathrm{ppm}$ at 25,40 and $60{ }^{\circ} \mathrm{C}$, respectively, after the addition of magnesium salt (the values referenced to the water signal in DMSO). The tendencies in the signal shifts upon temperature change appear to be identical, which means that with the temperature increase, the remaining signals are shifted upfield (Table 1).

Table 1. Signals (in ppm) in the ${ }^{1} \mathrm{H}$ NMR spectra of 7 registered at 25, 40 and $60{ }^{\circ} \mathrm{C}$, referenced to internal TMS

\begin{tabular}{ccccc}
\hline \multirow{2}{*}{ Signals } & & \multicolumn{3}{c}{ Temperature, ${ }^{\circ} \mathrm{C}$} \\
\cline { 3 - 5 } & & 25 & 40 & 60 \\
\hline without & $\mathbf{A}$ & 2.3787 & 2.3781 & 2.3781 \\
magnesium salt & $\mathbf{B}$ & 7.6512 & 7.6239 & 7.5966 \\
& $\mathbf{C}$ & 7.4463 & 7.4387 & 7.4312 \\
& $\mathbf{D}$ & 7.8681 & 7.8586 & 7.8501 \\
& $\mathbf{E}$ & 4.0900 & 4.0802 & 4.0730 \\
\hline after addition of & $\mathbf{A}-\mathbf{M g}$ & 2.3803 & 2.3807 & 2.3808 \\
magnesium salt & $\mathbf{B}-\mathbf{M g}$ & 7.6307 & 7.6093 & 7.5852 \\
& $\mathbf{C}-\mathbf{M g}$ & 7.4634 & 7.4580 & 7.4505 \\
& $\mathbf{D}-\mathbf{M g}$ & 7.8667 & 7.8555 & 7.8503 \\
& $\mathbf{E}-\mathbf{M g}$ & 4.0902 & 4.0837 & 4.0760 \\
\hline
\end{tabular}

We analysed five signals for protons A, B, C, D, as well as for E in the NMR spectrum recorded at $25^{\circ} \mathrm{C}$ (Scheme 1, Table 1, and Fig. 1; Tables S1-S6 and Fig S13-S20, supplementary material). 


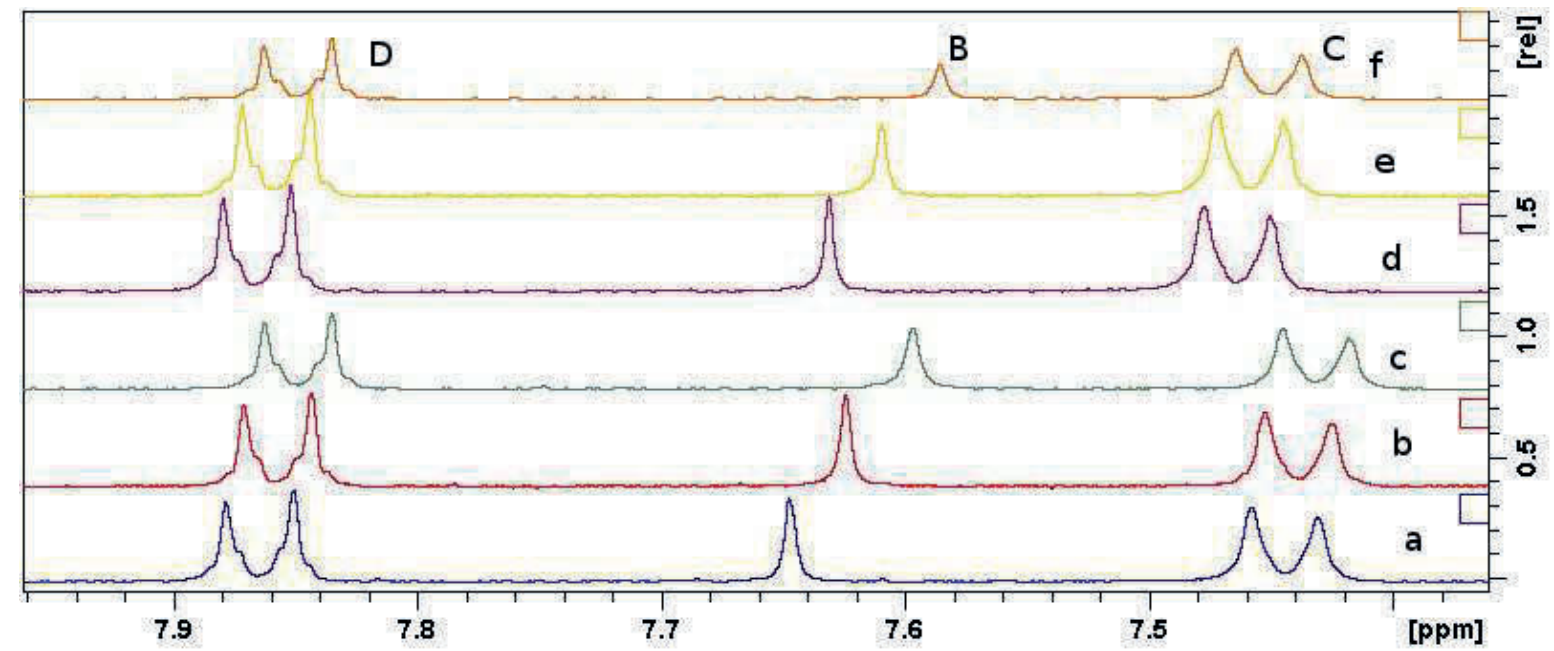

Figure. 1. Enhanced ${ }^{1} \mathrm{H}$ NMR spectra of aromatic region of compound 7 with $(\mathbf{d}-\mathbf{f})$ and without (a-c) magnesium salt taken at 25 (a or d), 40 (b or e) and $60{ }^{\circ} \mathrm{C}(\mathbf{c}$ or f).

The next step involved construction of a $5 \times 5$ matrix (MAT) for the intervals between signals. The results of the analysis of NMR spectra registered at 40 and $60{ }^{\circ} \mathrm{C}$ were elaborated identically (Tables S1-S6, supplementary material). Then, the matrices were subtracted for the visualisation of the interval changes in chemical shifts influenced by temperature. As a result a MAT40-MAT25 matrix and a $\mathrm{MAT}_{60}-\mathrm{MAT}_{40}$ matrix (without $\mathrm{Mg}^{2+}$ ) were obtained for temperatures 40 and $25^{\circ} \mathrm{C}$ as well as 60 and $40^{\circ} \mathrm{C}$, respectively. For the analysis of the obtained results a matrix was proposed in which colours were used instead of numbers (Fig. 2; Fig. S13-S17, supplementary material). The matrix reveals clearly that the largest temperature-dependent changes in chemical shifts for azole 7 refer to proton 3-H (B, Fig. S14, supplementary material). On the other hand, the presence of $\mathrm{Mg}^{2+}$ ions affects insignificantly the proton D signal of the tosyl substituent (Fig. 2; Fig. S15-S17, supplementary material). 

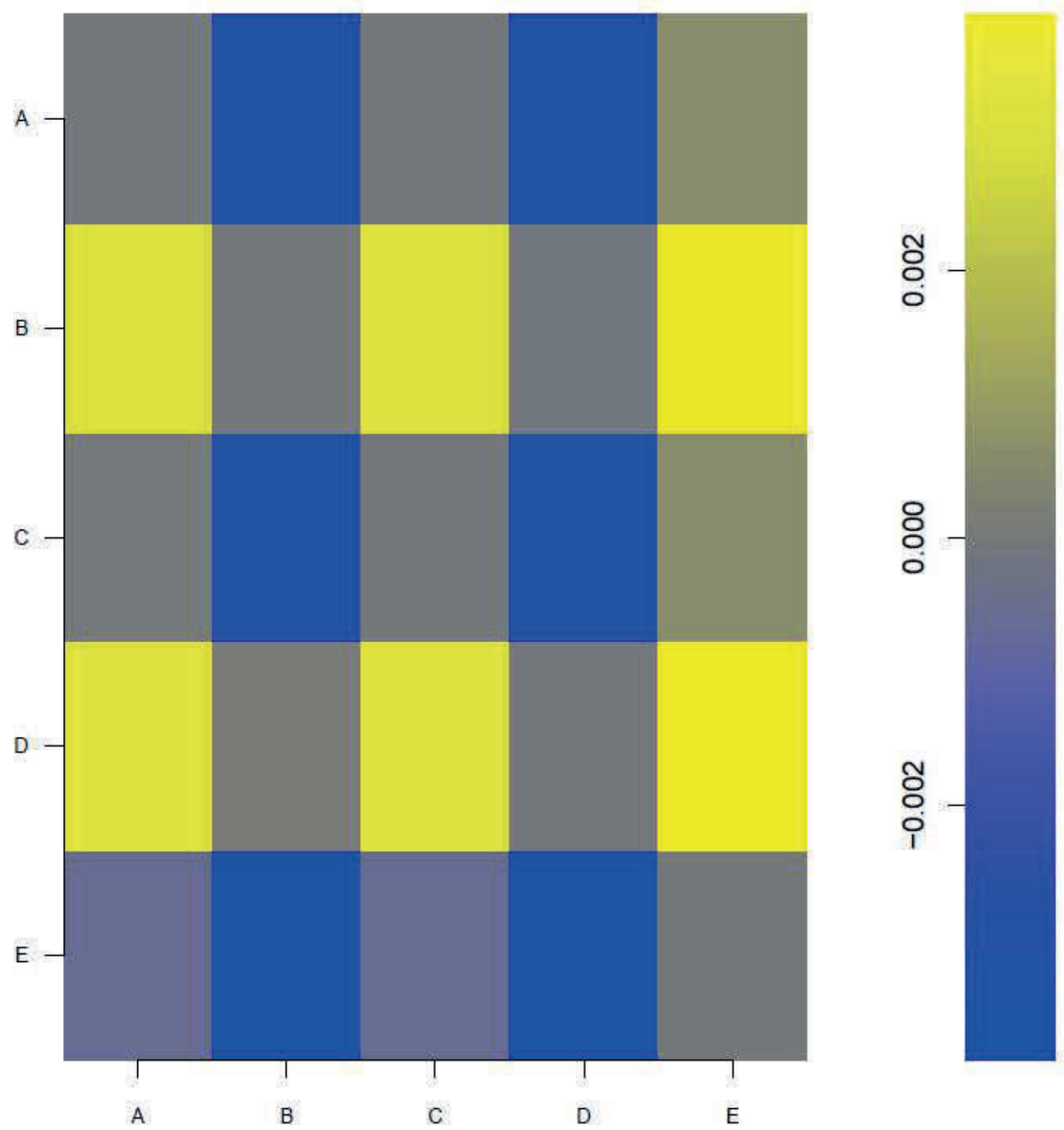

Figure. 2. Comparison of range changes between NMR signals of compound 7 before and after addition of magnesium salt at 40 and $60{ }^{\circ} \mathrm{C}$ : $\left(\mathrm{MAT}_{40}-\mathrm{MAT}_{60}\right)-\left(\mathrm{MATG}_{40}-\mathrm{MATG}_{60}\right)$.

In order to determine the magnesium salt impact on the change in chemical shifts as a temperature function (matrix MATG after addition of magnesium ions), the following equations were used: a) $\left(\mathrm{MAT}_{25}-\mathrm{MAT}_{40}\right)-\left(\mathrm{MATG}_{25}-\mathrm{MATG}_{40}\right)$, b) $\left(\mathrm{MAT}_{40}-\mathrm{MAT}_{60}\right)-\left(\mathrm{MATG}_{40}-\mathrm{MATG}_{60}\right)$. The results are gathered in a graphical form (Figs. 2; Fig. S17, supplementary material). Both graphics demonstrate that the chemical shift of protons B and D changes the most after the addition 
of magnesium salt. It means that magnesium is chelated in the close proximity to these protons (Scheme 1). Moreover, small changes of ca $0.002 \mathrm{ppm}$ of the chemical shifts of the tosyl C protons (Fig. S17, supplementary material), together with the above finding concerning D protons, may indicate that the neighbouring sulfonyl group is also engaged in the complexation. Interestingly, there are no apparent changes in the shifts of protons A (Tos methyl group) and E (N-methyl group). The latter observation implies that both nitrogens of the $\mathrm{N}$-substituted pyrazole part are not the complexation site.

We also measured the change in $\mathrm{pH}$ after the addition of magnesium salt: $\mathrm{pH}$ raised from 10.01 to 10.12 . That was a small change and therefore it was neglected. Usually, such small changes are omitted in this type of publications. ${ }^{24,25,30,31}$ The $\mathrm{pH}$ alterations, even small, should be considered if the molecule contains easily ionisable groups or for compounds of specific physicochemical properties (amino acids, proteins). They are unimportant for small molecules that, like compound 7, contain practically one protonation site. Additionally, we prove that such compounds do not tautomerise. ${ }^{11,25}$ Moreover, the matrices constructed in our paper cancel the effects of ionic strength and $\mathrm{pH}$, and show that the results are reproducible. It is interesting that the same tendency that determine the changes in chemical shifts was also observed when concentration of compound 7 was lowered (Table S7, supplementary material). The decrease in concentration allowed to eliminate potential influence of the $\mathrm{pH}$ alterations on the NMR analysis.

\section{Theoretical investigations}

As was suggested before, the investigations and understanding of the relationship between molecular structure and NMR parameters can sometimes be quite difficult, and therefore are often supported by theoretical calculations. The information gathered from quantum-chemical calculations, especially on solvation model and ion solvation sphere, is very valuable and allows for a rapid visualization of the results. This especially relates to the processes proceeding in solvents. The theoretical calculations of the chemical shifts for compound $\mathbf{7}$ were executed for all energy minima found during the alteration of C3-C2-S1-C1 dihedral angle effected by rotation in $10^{\circ}$ increments of the fused pyrazole moiety and tosyl fragment, respectively (optimization at the commonly used B3LYP/6-31G(d,p) level of theory); the four most stable rotamers I-IV are shown in Fig. 3. The calculations demonstrate that the energies of different tautomers of the same rotamer are essentially the same, the energy difference between tautomers is about 0.005 Hartree $(14.95 \mathrm{~kJ}$ $\left.\mathrm{mol}^{-1}\right)$. Therefore tautomerism involving protonation of the nitrogen atoms can be neglected in the above case as possible tautomeric variants of rotamers $\mathbf{I}-\mathbf{I V}$ of compound $\mathbf{7}$ have almost identical energy. The calculated proton chemical shifts for the optimized rotamers (the GIAO ${ }^{32,33}$ method, CPCM solvation model and water as a solvent) are generally accurate and consistent with the experimental values (Table 2). It is noteworthy that the dielectric constant values of water and DMSO are on a comparable level ( $\varepsilon=78.3$ and 46.8 , respectively) ${ }^{26,27,34}$ Moreover, the results of the NMR calculations carried out using DMSO as a solvent in comparison with the corresponding data for water are very similar. 
Table 2. Calculated and experimental data for ${ }^{1} \mathrm{H}$ NMR spectra of compound 7, rotamers I-IV; the following parameters were determined for the proton groups of the rotamers: experimental (Exp.) and calculated values of the chemical shifts (rotamers I-IV), percentage relative errors (E1$\mathrm{E} 4)$, mean values of the absolute and relative errors ( $\Delta \delta$ and $\mathrm{E}$, respectively; average); calculated $\mathrm{H}^{\mathrm{ref}}=31.7397 \mathrm{ppm}(\mathrm{GIAO}$ method), mean absolute deviation parameter $\mathrm{MAD}=0.92$

\begin{tabular}{ccccccccccccccc} 
& $\boldsymbol{E x p} \boldsymbol{.}$ & $\boldsymbol{I}$ & $\boldsymbol{\Delta} \boldsymbol{\delta} \boldsymbol{1}$ & $\boldsymbol{E} \boldsymbol{1}$ & $\boldsymbol{I I}$ & $\boldsymbol{\Delta} \boldsymbol{\delta} \boldsymbol{2}$ & $\boldsymbol{E} \boldsymbol{2}$ & $\boldsymbol{I I I}$ & $\boldsymbol{\Delta} \boldsymbol{\delta} \boldsymbol{3}$ & $\boldsymbol{E} \boldsymbol{3}$ & $\boldsymbol{I V}$ & $\boldsymbol{\Delta} \boldsymbol{\delta} \boldsymbol{4}$ & $\boldsymbol{E} \boldsymbol{4}$ & $\boldsymbol{E}$ \\
\hline $\mathbf{A}$ & 2.38 & 2.33 & 0.05 & 2 & 2.33 & 0.05 & 2 & 2.33 & 0.05 & 2 & 2.33 & 0.05 & 2 & 2 \\
B & 7.65 & 7.38 & 0.27 & 4 & 7.38 & 0.27 & 4 & 7.39 & 0.27 & 3 & 7.39 & 0.26 & 3 & 3 \\
NH & 13.67 & 9.49 & 4.19 & 31 & 9.48 & 4.2 & 31 & 9.48 & 4.19 & 31 & 9.49 & 4.19 & 31 & 31 \\
$\mathbf{C}$ & 7.45 & 8.04 & 0.59 & 8 & 8.03 & 0.59 & 8 & 8.03 & 0.59 & 8 & 8.03 & 0.59 & 8 & 8 \\
D & 7.87 & 7.55 & 0.31 & 4 & 7.55 & 0.31 & 4 & 7.55 & 0.32 & 4 & 7.55 & 0.32 & 4 & 4 \\
$\mathbf{E}$ & 4.09 & 4.21 & 0.12 & 3 & 4.22 & 0.13 & 3 & 4.22 & 0.13 & 3 & 4.2 & 0.11 & 3 & 3 \\
\hline
\end{tabular}
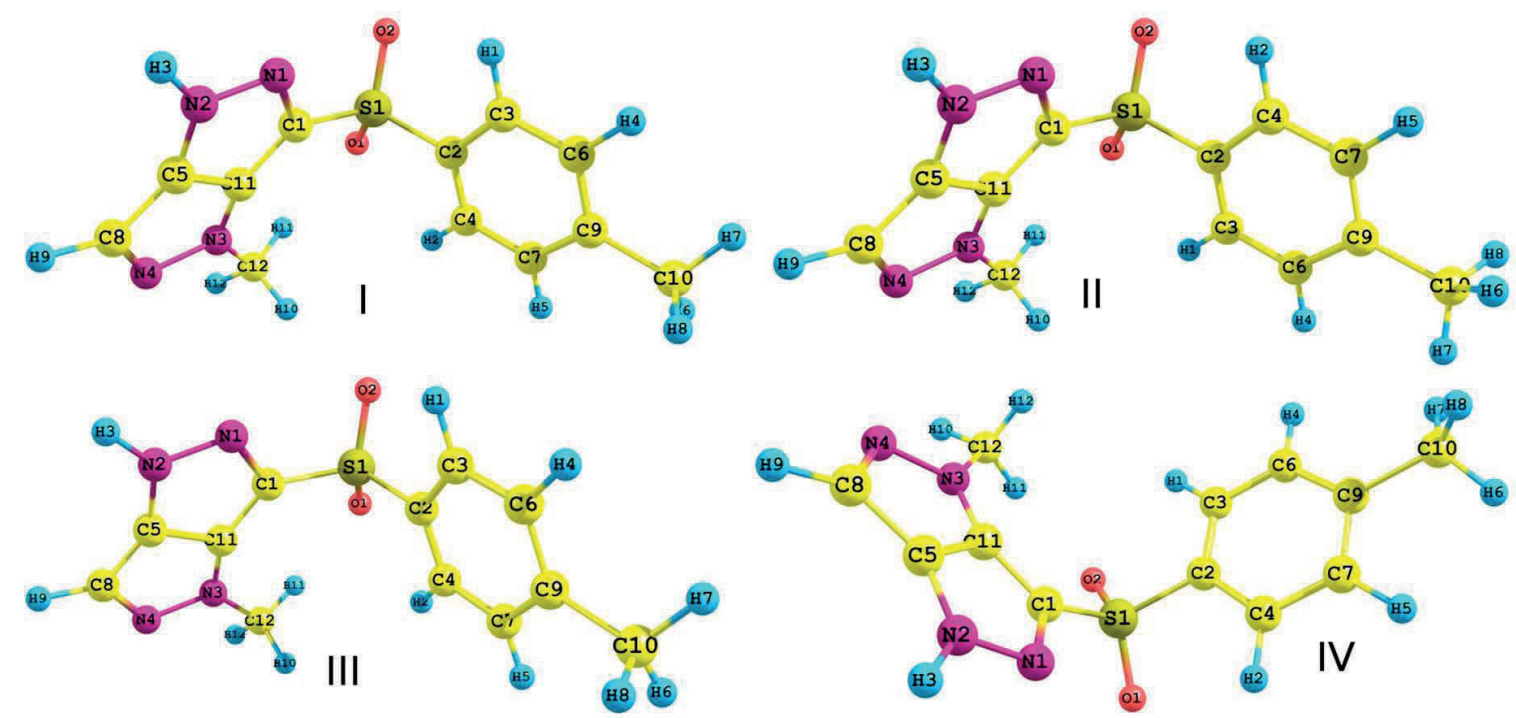

Figure. 3. Visualisation of the selected optimized rotamers of compound 7. The structures $\mathbf{I}-\mathbf{I V}$ were optimized at the B3LYP/6-31G(d,p) level of theory with CPCM solvent model.

The relative error for the $\mathrm{NH}$ group is large due to the $\mathrm{NH}$ proton exchangeability and dynamic dissociation equilibrium in the solvation sphere. This is supported by a simulation of NH proton interactions with a water molecule. The formation of a $\mathrm{N}-\mathrm{H} \cdots \mathrm{H}_{2} \mathrm{O}$ hydrogen bond results in a significant drop in the relative error down to $0.6 \%$. Furthermore, we have shown that the relative error for the methyl protons $\mathrm{A}$ and $\mathrm{E}$ is fairly small (Table 2 ) and equals to $2 \%$ for protons $\mathrm{A}$, and $3 \%$ for protons $\mathrm{E}$. The smaller error for the methyl protons A results from their deshielding and the lack of steric hindrance in contrast to the steric obstacle connected with the rotating tosyl and azole systems (protons E). In the latter case, the mean value for the distance between the $\mathrm{N}$-methyl 
protons $\mathrm{E}$ and the tosyl residue is $2.4 \AA$ at most. The theoretical NMR analysis shows also that the mean relative error for the phenyl protons $\mathrm{D}$ is $4 \%$. Thus it is notably smaller than for the phenyl protons $\mathrm{C}$ located closer to the sulfonyl group. The steric hindrance as well as electron withdrawing properties of the sulfonyl group results in an increase of the relative error of these protons shift to $8 \%$.

One limitation concerning the changes in chemical shifts in the theoretical spectrum of the compound 7-magnesium ion complex is the difficulty to combine conformational analysis with the correct estimation of both various interaction points and solvation sphere for magnesium ions. With this in mind, we carried out optimization of the compound 7-magnesium ion complex using the following models of rotamers (Fig. 4): 7- $\mathrm{Mg}\left(\mathrm{H}_{2} \mathrm{O}\right)_{6}(\mathbf{V}),{ }^{7}-\mathrm{Mg}(\mathrm{OH})^{+}(\mathbf{V I}),{ }^{7}-\mathrm{Mg}(\mathrm{OH})_{2}$ (VII). Moreover, we opted for the use of a cheaper, less time consuming GIAO method for the calculations involving $\mathbf{7 - M g}$ complexes (Table 3). The analysis of rotamers $\mathbf{V}-\mathbf{V I I}$ geometries shows that the $\mathrm{NH}$ and $\mathrm{CH}(\mathrm{B})$ bond lengths undergo changes after optimization $\left(\Delta_{\mathrm{NH}}=0.06,0.05\right.$ and $0.03 \AA$, respectively; $\Delta_{\mathrm{B}}=0.05,0.0002$ and $0.0001 \AA$, respectively). The results of the analysis of the chemical shifts for protons $\mathrm{A}-\mathrm{E}$ and $\mathrm{NH}$ are given in Table 3. It should be added that the use of computation method is tantamount with making assumptions concerning the ligand structure. The above findings seem to indicate that the rotamers in which the magnesium ion is close to the heterocyclic ring are the most appropriate. Moreover, to check accuracy of the computation model, the energy of the interaction $\mathrm{N}-\mathrm{H} \cdots \mathrm{O}-\mathrm{Mg}$ for rotamers $\mathbf{V}-\mathbf{V I I}$ (Fig. 4) was determined using the basis set superposition error (BSSE). ${ }^{35}$ This energy amounted to ca. $25.1 \mathrm{~kJ}$ $\mathrm{mol}^{-1}$ and is located within the energy limits for weak hydrogen bonds. This correlates well with the solvation of magnesium ions observed in our experiment. On the other hand, possibility of the direct contact of magnesium ions with the $\mathrm{N} 1$ nitrogen atom was ruled out due to the small value of the calculated coupling constant $J_{\mathrm{N}-\mathrm{Mg}}$ that was below the experimental error $(0.02 \mathrm{~Hz}, 0.03 \mathrm{~Hz}$, $0.04 \mathrm{~Hz}$ calculated at B3LYP/6-31G(d,p), CAM-B3LYP/6-31G(d,p), B3LYP/6-311+G(d,p) level of theory, respectively).

Table 3. Calculated and experimental data for ${ }^{1} \mathrm{H}$ NMR spectra of complex $\mathbf{7}-\mathbf{M g}$, rotamers $\mathbf{V}-$ VII; the following parameters were determined for the proton groups of the rotamers: experimental (Exp.) and calculated values of the chemical shifts (rotamers $\mathbf{V}-\mathbf{V I I}$ ), percentage relative errors (E5-E7), mean values of the absolute and relative errors ( $\Delta \delta$ and $\mathrm{E}$, respectively; average); calculated $\mathrm{H}^{\mathrm{ref}}=31.7397$ ppm (GIAO method), MAD $=0.63$.

\begin{tabular}{cccccccccccc} 
& $\boldsymbol{E x p}$. & $\boldsymbol{V}$ & $\boldsymbol{\Delta} \boldsymbol{\delta 5}$ & $\boldsymbol{E} 5$ & $\boldsymbol{V I}$ & $\boldsymbol{\Delta} \boldsymbol{\delta} \boldsymbol{6}$ & $\boldsymbol{E} \boldsymbol{6}$ & $\boldsymbol{V I I}$ & $\boldsymbol{\Delta \boldsymbol { \delta }} \boldsymbol{7}$ & $\boldsymbol{E} 7$ & $\boldsymbol{E}$ \\
\hline A & 2.38 & 2.25 & 0.13 & 6 & 2.48 & 0.1 & 4 & 2.32 & 0.06 & 2 & 4 \\
B & 7.65 & 7.18 & 0.47 & 6 & 7.69 & 0.04 & 0.5 & 7.45 & 0.2 & 3 & 3 \\
NH & 13.67 & 8.49 & 5.18 & 38 & 16.12 & 2.44 & 18 & 13.7 & 0.03 & 0.2 & 19 \\
C & 7.45 & 7.51 & 0.07 & 0.9 & 7.7 & 0.26 & 3 & 8 & 0.55 & 7 & 4 \\
D & 7.87 & 7.31 & 0.56 & 7 & 7.6 & 0.27 & 3 & 7.54 & 0.33 & 4 & 5 \\
E & 4.09 & 4.46 & 0.37 & 9 & 4.39 & 0.3 & 7 & 4.15 & 0.06 & 2 & 6
\end{tabular}




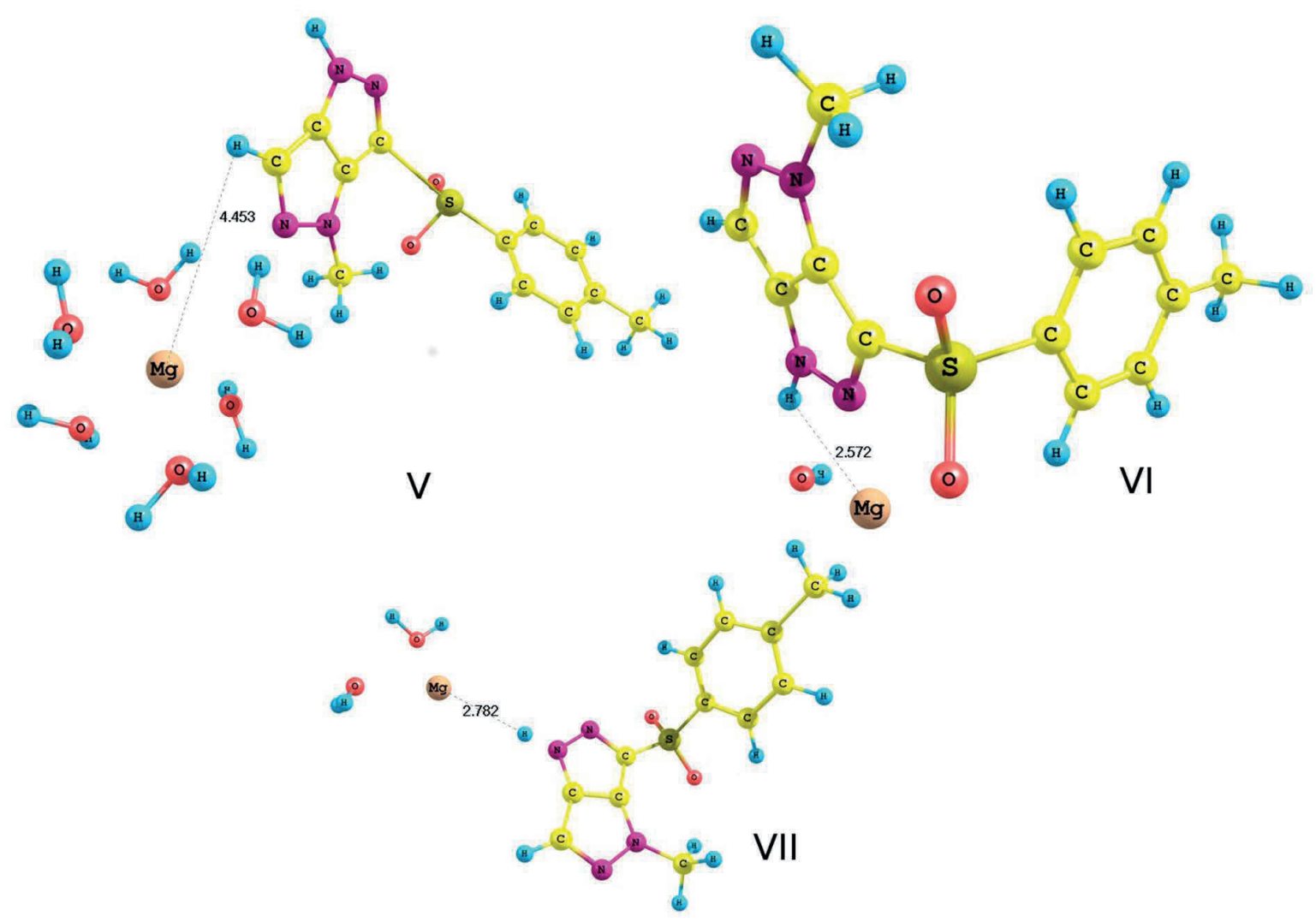

Figure. 4. Binding modes of $\mathrm{Mg}^{2+}$ cations to compound 7. The structures $\mathrm{V}-\mathrm{VII}$ were optimized at the B3LYP/6-31G(d,p) level of theory with CPCM solvent model.

Basing on NMR experiments, we claim that chemical shifts of protons B and D change the most upon interaction. However, the data in Tables 1, S1-S6 (supplementary material) indicate that the changes in $\mathrm{C}$ and $\mathrm{D}$ protons chemical shifts are slight. This is probably due to the migration of magnesium cations around the phenyl moiety during optimization caused by the close proximity of the sulphonyl group. Additionally, the results of calculations given in Table 4 and Fig. 5 (rotamer VIII) proved the possible influence of the presence of magnesium ions on changes in chemical shifts of proton $\mathrm{A}-\mathrm{E}$ and $\mathrm{NH}$ of azole 7, especially $\mathrm{A}-\mathrm{D}$. Noteworthy is good agreement of the calculated chemical shifts with the experimental values. 
Table 4. Calculated and experimental data for ${ }^{1} \mathrm{H}$ NMR spectra of complex $7-\mathbf{M g}(\mathbf{H 2 O})^{+}$, rotamer VIII; the following parameters were determined for the proton groups of the rotamers: experimental (Exp.) and calculated values of the chemical shifts (rotamer VIII), mean values of the absolute and percentage relative errors $\left(\Delta \delta 8\right.$ and $\mathrm{E}$, respectively); calculated $\mathrm{H}^{\mathrm{ref}}=31.7397$ ppm (GIAO method), MAD $=0.49$.

\begin{tabular}{ccccc} 
& $\boldsymbol{E x p}$ & $\boldsymbol{V I I I}$ & $\boldsymbol{\Delta} \delta \boldsymbol{8}$ & $\boldsymbol{E}$ \\
\hline A & 2.38 & 2.44 & 0.06 & 2 \\
B & 7.65 & 7.90 & 0.25 & 3 \\
NH & 13.67 & 12.45 & 1.23 & 8 \\
C & 7.45 & 8.32 & 0.87 & 11 \\
D & 7.87 & 7.77 & 0.10 & 1 \\
E & 4.09 & 4.52 & 0.43 & 10
\end{tabular}

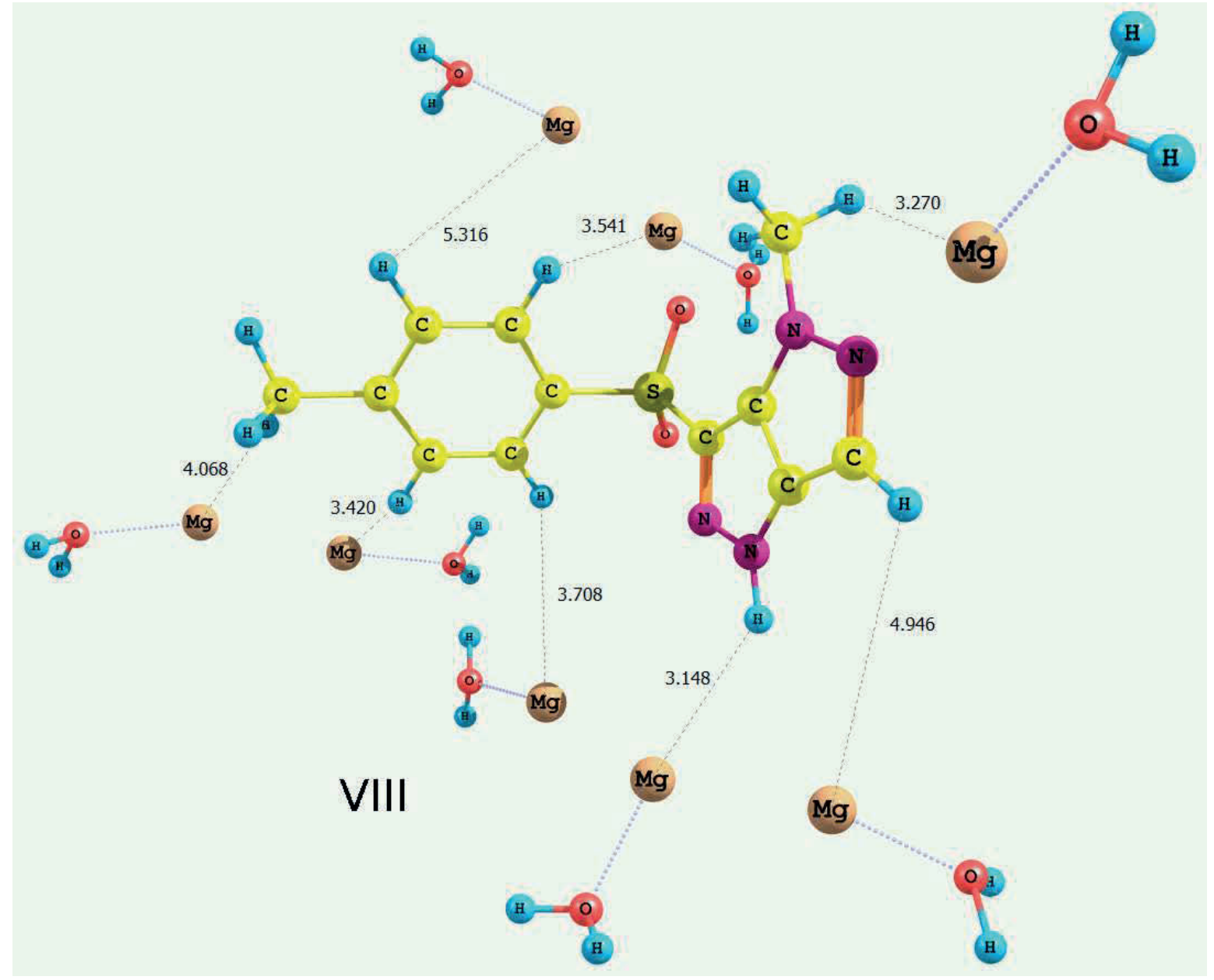

Figure. 5. Binding modes of $\mathrm{Mg}\left(\mathrm{H}_{2} \mathrm{O}\right)^{+}$cations to compound 7. The structure VIII was optimized at the B3LYP/6-31G(d,p) level of theory with CPCM solvent model. 
Table 5. Calculated and experimental data for the ${ }^{1} \mathrm{H}$ NMR spectra of complex 7- $\left[\mathbf{M g}\left(\mathbf{H}_{2} \mathbf{O}\right)_{5}(\mathbf{O H})\right]-7$ (rotamers IX $\left.-\mathbf{X}\right)$; the following parameters were determined for the proton groups of the rotamers: experimental (Exp.) and calculated values of the chemical shifts (rotamers $\mathbf{I X}-\mathbf{X})$, percentage relative errors (E9-E10), mean values of the absolute and relative errors $(\Delta \delta$ and $\mathrm{E}$, respectively; average); calculated $\mathrm{H}^{\mathrm{ref}}=31.7397$ ppm (GIAO method), mean absolute deviation parameter $\mathrm{MAD}=1.04$ and 1.03

\begin{tabular}{cccccccc} 
& $\boldsymbol{E x p}$. & $\boldsymbol{I} \boldsymbol{X}$ & $\boldsymbol{\Delta} \boldsymbol{\delta} \boldsymbol{9}$ & $\boldsymbol{E 9}$ & $\boldsymbol{X}$ & $\boldsymbol{\Delta} \boldsymbol{\delta} \boldsymbol{1 0}$ & $\boldsymbol{E} 10$ \\
\hline A & 2.38 & 2.22 & 0.16 & 7 & 2.21 & 0.17 & 7 \\
B & 7.65 & 6.86 & 0.79 & 10 & 6.76 & 0.89 & 12 \\
NH & 13.67 & 9.52 & 4.16 & 30 & 9.88 & 3.80 & 28 \\
C & 7.45 & 7.85 & 0.41 & 5 & 7.99 & 0.54 & 7 \\
D & 7.87 & 7.25 & 0.62 & 8 & 7.24 & 0.63 & 8 \\
E & 4.09 & 4.00 & 0.09 & 2 & 3.97 & 0.12 & 3 \\
\hline
\end{tabular}

The final stage of the DFT calculations was devoted to investigation of two molecules of 7 that coordinate one hydrated magnesium cation. This led to additional two rotamers $\mathbf{I X}$ and $\mathbf{X}$ in which an important feature of the realistic system was included. Probably at the experimental basic $\mathrm{pH}$, the hydration shell of the magnesium cation includes at least one hydroxyl ion due to the interplay between basicity of $\mathrm{Mg}^{2+}$ and nitrogen atoms of compound 7. The starting points for the two optimizations assumed different numbers of the $\mathrm{OH}^{-}$moieties in the complex, but finally the two complexes turned out to be rotamers of 7-[Mg( $\left.\left.\mathbf{H}_{2} \mathbf{O}\right)_{5}(\mathbf{O H})\right]-7$. This, however, has a little effect on the signals of $\mathrm{C}-\mathrm{H}$ protons $\mathrm{A}-\mathrm{E}$ (Table 5) with notable exception of the proton $\mathrm{B}$ that moves upfield from ca $7.5 \mathrm{ppm}$ in complexes IV-VIII to ca $6.8 \mathrm{ppm}$ in complexes IX and $\mathbf{X}$ (Fig. 6). This is due to a change of theoretically possible protonation site in the azole system. However, such a strong shift was not observed experimentally. Therefore, proton $\mathbf{B}$ is indeed among the most perturbed atoms upon addition of the magnesium salt (Table 1). This points out to a conclusion that, regardless whether hydroxyl ions are present or not in the coordination sphere of the magnesium cation, the protonated species of compound $\mathbf{7}$ and the presence of the hydroxyl anion are insignificant in the solution under these experimental conditions. 

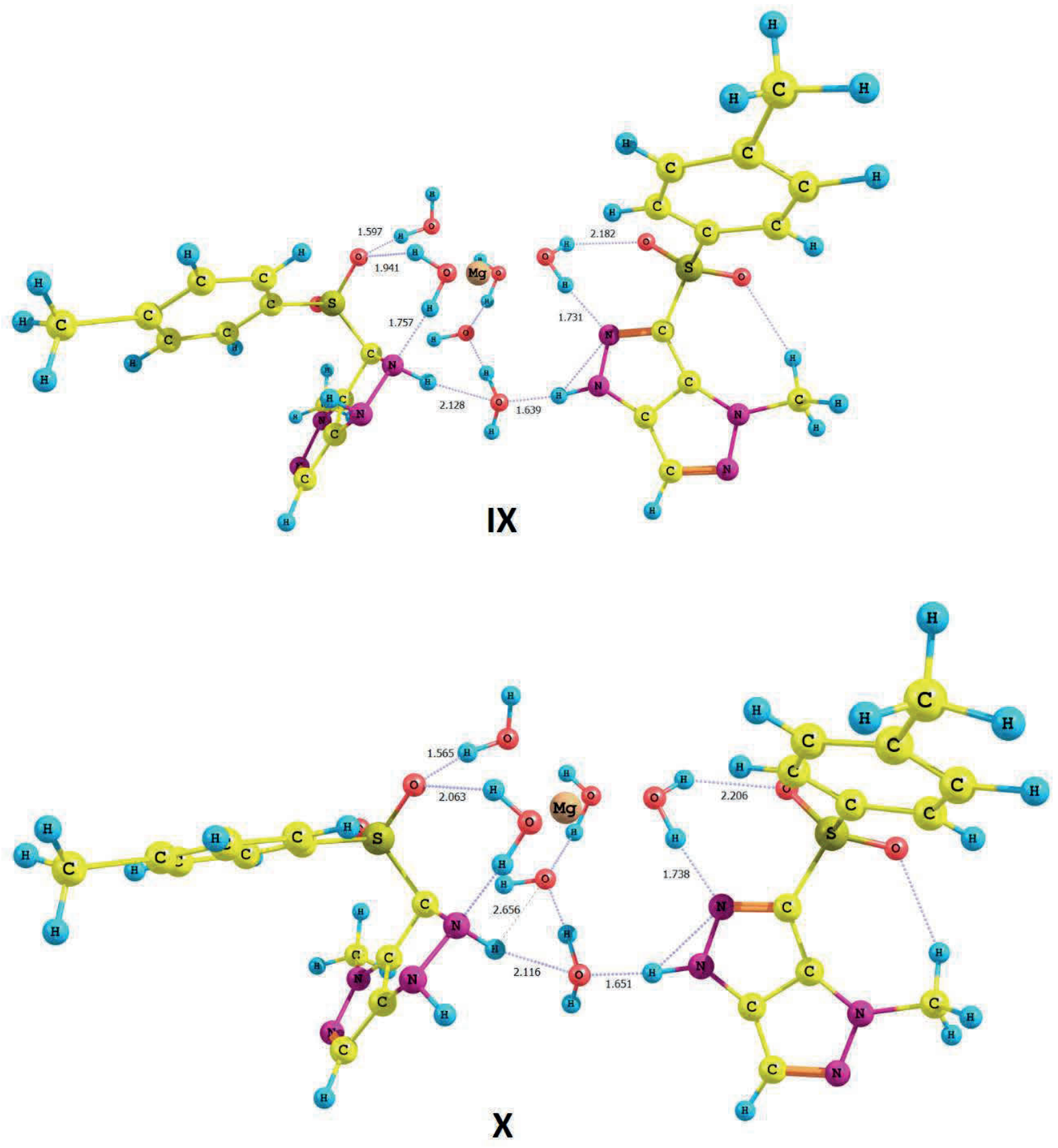

Figure. 6. Binding modes of complexes of compound 7. The structures of $\mathbf{I X}-\mathbf{X}$ were optimized at the B3LYP/6-31G(d,p) level of theory with CPCM solvent model.

The DFT calculations reveal that multiple positions are attainable for the interactions between 7 and $\mathrm{Mg}^{2+}$. An approximate insight into their relative importance can be gained by molecular dynamics simulation with classical force field (GAFF). ${ }^{36}$ The model employed in our study is a 
single molecule of 7 together with one $\mathrm{Mg}^{2+}$ cation solvated in a $30 \AA$ cubic box of TIP3P water ${ }^{37}$. The resulting radial pair distance distribution functions for the contacts between magnesium cation and selected atoms of 7 are presented in Fig. 7. Evidently, and in agreement with the strong negative electrostatic potential of the sulphonyl oxygen atoms, they are the primary contacts for the $\mathrm{Mg}^{2+}$. The cation visits also the vicinity of $\mathrm{N} 1$, and also the $\mathrm{NH}$ moiety. However, its contacts with the $\mathrm{C}$ protons of the phenyl ring are much closer $(4-5.5 \AA)$ than with the proton $\mathrm{B}(7-8 \AA)$. Thus, the experimental observations of slight, but rather similar changes of the ${ }^{1} \mathrm{H}$ NMR signals of $\mathrm{B}$ and $\mathrm{C}$ upon addition of the $\mathrm{Mg}$ salt suggests that the interaction of the cation with the phenyl ring changes its properties by a "through-space" mechanism. The change in chemical shifts of the $\mathrm{CH}$ moiety and the associated proton $\mathrm{B}$ is rather propagated through the molecular skeleton, or induced by changes in the solvation sphere.

Prediction of the accurate solvation sphere, conformation and site of the azole-ligand interaction seem to be a complicated process, and we intend to improve the procedure in future. Nevertheless, the depicted herein theoretical calculations have provided an interesting visualization of compounds complex from the quantum chemistry standpoint.

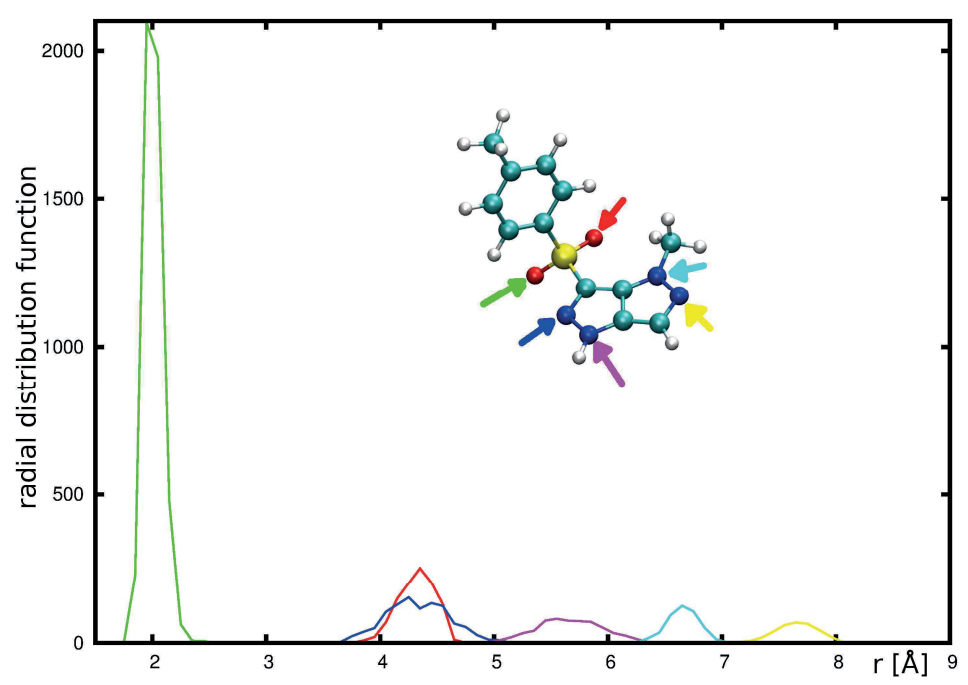




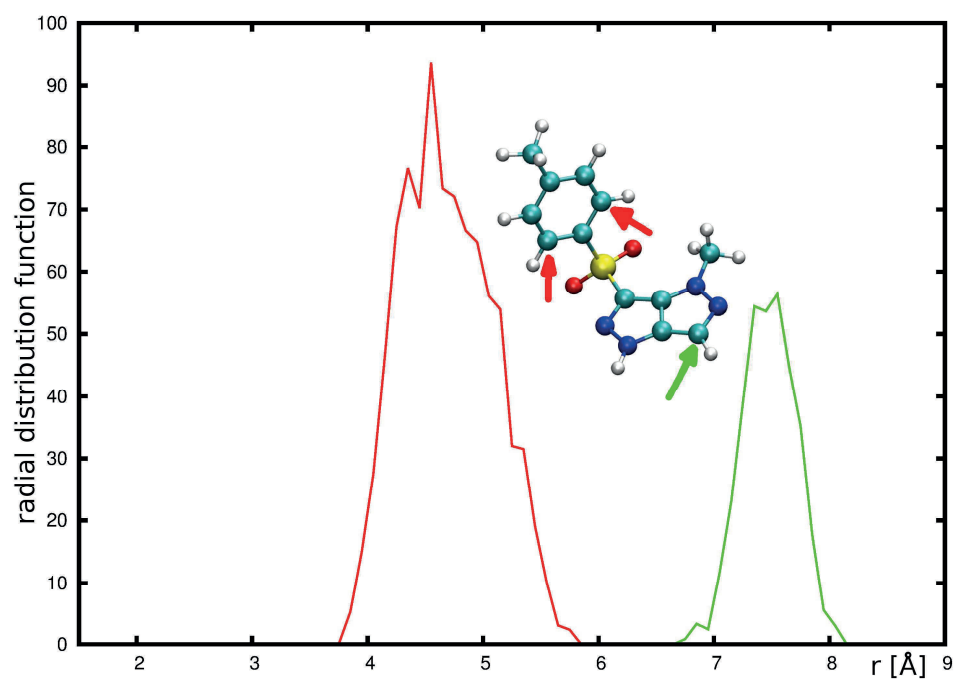

Figure 7. Radial distribution function of distances between the magnesium cation and the indicated atoms of compound 7 resulted from the classical molecular dynamics simulation.

\section{Conclusions}

The above discussed method is fast and cheap and enables to follow changes in chemical shifts with no need for time-consuming use of reference compounds and various solvents. We have proved that reliable results can be obtained from the comparative analysis of the changes in chemical shifts in complexes at different temperatures. A potential application of the method has been checked on a model NMR analysis at 25,40 and $60^{\circ} \mathrm{C}$ for the condensed pyrazole derivative 7 and its complex with magnesium ions. The interactions have also been investigated by DFT calculations performed for several rotamers of compound 7 before and after complexation; a stoichiometry of $7-\mathrm{Mg}-\mathbf{7}$ was also considered. Basing on the analysis of changes in chemical shifts and matrix operations we have identified the sites susceptible to interactions with magnesium ions, i.e. the pyrazole nitrogens of the $\mathrm{N}$-unsubstituted heterocyclic part of the condensed pyrazole derivative 7 . We have also evidenced that the adduct $7-\mathrm{Mg}$ can additionally be stabilised by the sulfonyl group of the tosyl substituent.

The above approach can be used for the analysis of interactions ligand-protein, between a couple of organic compounds, biofluids with metal salts and biofluids with metabolites based on further statistical tests. 


\section{Experimental Section}

General. The reactions progress and purity of the products were monitored by TLC using silica gel plates Kieselgel $60 \mathrm{~F}_{254}$ (Merck). Melting points were determined on a Boetius apparatus and are uncorrected. The ${ }^{1} \mathrm{H}$ NMR and ${ }^{13} \mathrm{C}$ NMR spectra were recorded in 5-mm NMR tubes Norrell XR-55 on a Bruker Avance III $300 \mathrm{MHz}$ NMR spectrometer equipped with a variable temperature unit VTU 3200 (300 and $75 \mathrm{MHz}$ ) using TMS as internal standard. The temperature of the probe head was calibrated with perdeuterated methanol according to Berger with perdeuterated methanol assuming a linear correlation of temperature and shift differences ${ }^{38}$ For temperature-dependent ${ }^{1} \mathrm{H}$ NMR measurements stock solutions of the compounds with ca. $1 \mathrm{mg}$ of material were dissolved in the appropriate amount of DMSO- $d_{6}$. After mixing the solutions by vortexing the NMR sample tubes and turning them several times upside down, the NMR samples were thermostatted for at least $10 \mathrm{~min}$ at the appropriate temperature $(298,313$, and $333 \mathrm{~K})$ in the probe head and, after determination of the water resonance a 1D NOESY spectrum with gradient purge pulses and with a delay time of $10 \mathrm{~ms}$ was recorded (manufacturer's pulse program noesyldpr). For the recording of the ${ }^{1} \mathrm{H}$ NMR spectra, four dummy scans were used and 64 scans were accumulated with an interpulse delay of $3.5 \mathrm{~s}$. Thereby 32768 data points were collected with a sweep-width of 16.0 ppm, which were for resolution enhancement zero-filled to 131072 data points before fouriertransformation. For the recording of the ${ }^{13} \mathrm{C}$ NMR spectra with proton decoupling at $298 \mathrm{~K}$, fivefold concentrated solutions were employed and a pulse program was used with an acquisition time of about $0.4 \mathrm{~s}, 10000$ scans and an interpulse delay of $2 \mathrm{~s}$ (manufacturer's pulse program udeft, with a flip back pulse at the end of acquisition to reduce the interpulse delay ${ }^{39}$ ). Linear prediction to about 262000 data points was made. The ${ }^{13} \mathrm{C}$ spectra were calibrated with either an external solution of TMS in DMSO- $d_{6}$ or TMS in DMSO- $d_{6}$ with a large excess of magnesium nitrate hexahydrate salt. The characterization of the compound 7 was performed with higher concentrated solutions $\left(2.50 \mathrm{mg}\right.$ in $450 \mu \mathrm{l}$ of DMSO- $d_{6}$ ), that is a standard for H,H-COSY, H,C-HSQC, H,CHMBC and H,H-NOESY experiments. In order to discriminate protons, they were marked according to Scheme 1 (values in ppm): positions: A 2.38, s; B 7.65, s; C 7.43-7.46, m AA'XX'; D 7.85-7.88, m AA'XX'; E 4.09, s; NH 13.67, bs. Low resolution MS spectra were taken on an AMD 402 instrument. IR spectra were recorded on a Specord 75-IR apparatus. Elemental analyses were performed on a Vario EL III instrument. Starting materials 3, 4, and 5 were obtained according to known methods. ${ }^{28,40,41}$ Moreover, values of chemical shifts were directly taken from FID files (ASCII files recorded in TopSpin), and all experiments were correctly calibrated. It is worth mentioning that the changes in chemical shifts were caused not by a potential field drift, but by the interactions of the analyte with environment. This conclusion is proved by the matrix operations described in the present paper that shows that the significant changes in chemical shifts correspond only to protons $\mathrm{NH}$ and B-D of azole 7. 


\section{Synthesis and spectroscopic data}

4-Amino-1-methyl-5-[(4-toluenesulfonyl)methyl]-1H-pyrazole (6). Hydrazine hydrate $(d=$ $\left.1.032 \mathrm{~g} \mathrm{ml}^{-1}, 12 \mathrm{ml}\right)$ and a suspension of Raney nickel $(50 \mathrm{~mL})$ were added to a solution of nitroarene $5(2.07 \mathrm{~g}, 7 \mathrm{mmol})$ in a mixture of THF $(75 \mathrm{~mL})$ and methanol $(115 \mathrm{~mL})$. The resulting mixture was heated under reflux for 10 minutes and filtered through Celite. The solvent was distilled off under reduced pressure and the residue was crystallized from ethanol to afford compound 6 as reddish prisms, mp $136-140{ }^{\circ} \mathrm{C} .{ }^{1} \mathrm{H}$ NMR $\left(300 \mathrm{MHz}\right.$, acetone- $\left.d_{6}\right) \delta: 2.46(\mathrm{~s}, 3 \mathrm{H}$, $\left.\mathrm{CH}_{3}, \mathrm{Ts}\right), 3.47$ (s, 3H, N-CH $), 4.04$ (bs, $2 \mathrm{H}, \mathrm{NH}_{2}$ exchangeable with $\left.\mathrm{D}_{2} \mathrm{O}\right), 4.54\left(\mathrm{~s}, 2 \mathrm{H}, \mathrm{CH}_{2}\right)$, 7.29-7.35 (m, 3H, 3-H, 3'-H and 5' -H, Ts+3-H), 7.65-7.68 (m, 2H, 2'-H and 6'-H, Ts). MS m/z ( \%): 265 (100), 221 (2), 200 (2), 149 (2), 110 (84), 91 (5), 56 (25), 55 (5). Anal. calcd for $\mathrm{C}_{12} \mathrm{H}_{15} \mathrm{~N}_{3} \mathrm{O}_{2} \mathrm{~S}$ (265.33): C 54.32; H 5.70; $\mathrm{N}$ 15.84. Found: C 54.71; H 5.52; N 15.54.

1-Methyl-6-(4-toluenesulfonyl)-4H-pyrazolo[4,3-c]pyrazole (7). Amine 6 (0.24 g, 0.9 mmol) was adsorbed on silica gel $(1 \mathrm{~g})$ and transferred into a pressure tube $(15 \mathrm{~mL})$. The solid was treated with 2-methylbutyl nitrite $\left(d=0.872 \mathrm{~g} \mathrm{~mL}^{-1}, 0.24 \mathrm{~mL}, 1.8 \mathrm{mmol}\right)$ and a small amount $(0.5-1 \mathrm{~mL})$ of acetic acid. The mixture was heated in a microwave reactor (Plazmatronika RM800) for 5 min. The product was extracted with $\mathrm{CH}_{2} \mathrm{Cl}_{2}(5 \times 10 \mathrm{~mL})$, then the organic extract was filtered, washed with water and dried. The solvent was removed and the residue was crystallized from methanol to afford compound $7(0.14 \mathrm{~g}, 57 \%)$ as white plates, mp $148-150{ }^{\circ} \mathrm{C} .{ }^{1} \mathrm{H}$ NMR (300 MHz, DMSO$\left.d_{6}\right) \boldsymbol{\delta}: 2.38\left(\mathrm{~s}, 3 \mathrm{H}, \mathrm{CH}_{3}\right), 4.09$ (s, 3H, N-CH $\left.\mathrm{CH}_{3}\right), 7.43-7.46(\mathrm{~m}, 2 \mathrm{H}, \mathrm{Ts}), 7.65$ (s, 1H, 3-H), 7.85-7.88 (m, 2H, Ts), 13.67 (s, 1H, NH, exchangeable with $\left.\mathrm{D}_{2} \mathrm{O}\right) .{ }^{13} \mathrm{C}$ NMR $\left(75 \mathrm{MHz}, \mathrm{DMSO}-d_{6}\right) \delta: 21.0$ ( $\left.\mathrm{CH}_{3}-4 ”\right), 38.0\left(\mathrm{CH}_{3}-1\right), 118.5$ (C-3), 127.2 (C-3”, C-5”), 130.1 (C-2”, C-6”), 133.6 (C-6'), 130.5 (C-6), 138.2 (C-1"), 140.1 (C-3'), 144.5 (C-4").

The signals were assigned using the COSY, NOESY, HSQC and HMBC spectra. MS $m / z(\%): 276$ (100), 248 (2), 211 (10), 183 (4), 155 (2), 121 (7), 91 (90), 67 (11), 43 (3). Anal. calcd for $\mathrm{C}_{12} \mathrm{H}_{12} \mathrm{~N}_{4} \mathrm{O}_{2} \mathrm{~S}$ (276.31): C 52.16; H 4.38; N 20.28. Found: C 52.57; H 4.17; N 20.49.

\section{Procedure for the preparation of sample solutions for the NMR analyses}

Solution 1 (Sol 1): $0.30 \mathrm{mg}$ of compound 7 in $0.2 \mathrm{~mL}$ of DMSO- $d_{6}$.

Solution 2 (Sol 2): $0.041 \mathrm{~g}$ of $\mathrm{Mg}\left(\mathrm{NO}_{3}\right)_{2} \times 6 \mathrm{H}_{2} \mathrm{O}$ in $0.4 \mathrm{~mL}$ of DMSO- $d_{6}$ (concentration: $0.4 \mathrm{~mol}$ $\left.\mathrm{L}^{-1}\right)$.

Sample 1 (the reference sample): $0.2 \mathrm{~mL}$ of Sol 1 in $0.4 \mathrm{~mL}$ of DMSO- $d_{6}$.

Sample 2: $0.2 \mathrm{~mL}$ of Sol 1 + 0.4 mL of Sol 2 .

The ${ }^{1} \mathrm{H}$ NMR spectra were registered for Sample 1 and Sample 2 at 25, 40 and $60{ }^{\circ} \mathrm{C}$.

\section{Theoretical calculations}

The theoretical DFT calculations were executed using Gaussian G09 D.01 suite code. ${ }^{34}$ The structures of the different rotamers of compound 7 were optimized (no negative frequencies were observed in the generated vibrational spectrum of the optimized rotamers) using the density functional theory (DFT) ${ }^{42}$ with the commonly used B3LYP ${ }^{43}$ functional and standard basis 6$31 \mathrm{G}(\mathrm{d}, \mathrm{p}) .{ }^{44}$ The solvent effect on the geometry of compound $\mathbf{7}$ and complex 7-Mg was determined 
using a conductor-like polarized continuum (CPCM) model (water as a solvent). ${ }^{45}$ Vibrational frequencies and thermodynamic properties were calculated applying the ideal gas, rigid rotor, and harmonic oscillator approximations. ${ }^{46}$ Energy minimum was confirmed by the frequency calculation for all rotamers (no negative frequencies were detected in the generated vibrational spectrum of the analyzed rotamers). The initial structures of magnesium complex 7-Mg were designed by a change in the $\mathrm{C} 3-\mathrm{C} 2-\mathrm{S} 1-\mathrm{C} 1$ torsion angle and rotation of the tosyl group. The NMR parameters, were calculated using the coupled perturbed density functional theory (CP-DFT $)^{47}$ method with B3LYP functional. This functional has been found to be in good agreement with experimental data. ${ }^{48}$ The calculations were performed using the NMR dedicated $\mathrm{GIAO}^{32}$, 33 method. The same solvent models as employed for the geometry optimization were used in the calculation of scalar couplings. ${ }^{44}$ The proton chemical shifts were referenced to the central signal of TMS. The proton shift equalled $31.7397 \mathrm{ppm}$ (for B3LYP/GIAO//B3LYP/6-31G(d,p) approach). The shifts of compound 7 and reference TMS were calculated using the same method whereas the reference TMS was used to obtain the chemical shifts of 1 according to the following equation: $\delta_{\mathrm{i}}=\sigma_{\text {ref }}-\sigma_{\mathrm{i}}$, where $\delta_{\mathrm{i}}$ was the chemical shift of i-nuclei of $\mathbf{1}$ and $\sigma_{\text {ref }}$ and $\sigma_{\mathrm{i}}$ were the calculated isotropic magnetic shielding tensor for the TMS and 1, respectively. ${ }^{26,27,50}$ The calculated chemical shifts for the homotopic protons were averaged. The Chemcraft 1.7 software was utilized for visualization of all optimized rotamers. ${ }^{51}$

The classical molecular dynamics calculations with the GROMACS 5.0.5 suite ${ }^{52}$ employed the GAFF general organic force field ${ }^{36}$ and TIP3P water model ${ }^{37}$. The molecule of 7 was immersed in a $30 \AA$ cubic box of water and a randomly placed magnesium cation was added. To remove bad contacts, 100 steps of minimization was carried out, then a two-stage equilibration was performed. First, an NVT (constant number, volume, and temperature conditions) run at $300 \mathrm{~K}$ was carried out for $0.3 \mathrm{~ns}$, and then an NPT (constant number, pressure, and temperature conditions) run at $300 \mathrm{~K}$ and $1 \mathrm{~atm}$ was performed for $0.2 \mathrm{~ns}$. Finally the NPT production run lasted for $5 \mathrm{~ns}$. The timestep was $1 \mathrm{fs}$, and PME electrostatics with $10 \AA$ real space nonbonded cutoff was employed. The trajectory was analysed using the $V M D$ 1.9.1 program. $^{53}$

\section{Acknowledgements}

This study was supported by SBN Grants No. 174/2013 and 88/2015 (Poznan University of Medical Sciences), as well as PCSS (Poznan Supercomputing and Networking Center) Grant No. 199/2014 and Wrocław Center for Networking and Supercomputing (WCSS) Grant No. 327/2014. It was additionally carried out in cooperation with the Research and Development Laboratory of RootInnovation. 


\section{Supplementary materials}

The Cartesian coordinates for the compound 7 and the solvation models for it magnesium complex 7-Mg, NMR spectroscopic data for compounds 4-7, as well as changes in chemical shifts are available in the supporting material. Supplementary data associated with this article can be found, in the online version, at doi.

\section{References}

1. Chauhan, A.; Sharma, P. K.; Kaushik, N. Int.J. ChemTech Res. 2011, 3, 11. http://www.sphinxsai.com/Vol.3No.1/chem jan-mar11/pdf/CT=02\%28\%201117\%29\%20JMCT11.pdf

2. Li, J. J. Pyrazoles, Pyrazolones, and Indazoles in Heterocyclic Chemistry in Drug Discovery, John Wiley \& Sons, Hoboken (New Jersey), 2013, pp 198-229.

3. Jamwal, A.; Javed, A.; Bhardwaj, V. J. Pharm. BioSci. 2013, 3, 114. http://www.jpbs-online.com/admin/php/uploads/20 pdf.pdf

4. Pérez-Fernández, R.; Goya, P.; Elguero, J. Arkivoc 2014, 2, 233. http://dx.doi.org/10.3998/ark.5550190.p008.131

5. Avendaňo, C.; Menéndez, J. C. Medicinal Chemistry of Anticancer Drugs, Elevier, Amsterdam, 2008.

6. Kumar, H.; Saini, D.; Jain, S.; Jain, N. Eur. J. Med. Chem. 2013, 70, 248. http://dx.doi.org/10.1016/j.ejmech.2013.10.004

7. Nishizawa, Y.; Morii, H.; Durlach, J. New Perspectives in Magnesium Research. Nutrition and Health, Springer Verlag: London, 2006.

8. Wolf, F. I; Maier, J. A. M.; Nasulewicz, A.; Feillet-Coudray, C.; Simonacci, M.; Mazur, A.; Cittadini, A. Arch. Biochem. Biophys. 2007, 458, 24.

http://dx.doi.org/10.1016/j.abb.2006.02.016

9. Wolf, F. I.; Cittadini, A. R. M.; Maier, J. A. M. Cancer Treat. Rev. 2009, 35, 378.

10. Totoń, E.; Igantowicz, E.; Bernard, M. K.; Kujawski, J.; Rybczyńska, M. J. Physiol. Pharmacol. 2013, 64,115.

http://dx.doi.org/10.1016/j.ctrv.2009.01.003

11. Kujawski, J.; Czaja, K.; Doskocz, M.; Bernard, M. K.; Drabińska, B.; Kruk, J.; Myka, A. Comput. Theor. Chem. 2015, 1059, 45.

http://dx.doi.org/10.1016/j.comptc.2015.02.013

12. Lehmann, T.; Kujawski, J.; Jagodziński, P.; Bernard, M. K. unpublished data, 2014.

13. Indra Neela, Y.; Subha Mahadevi, A.; Narahari Sastry, G. Struct. Chem. 2013, 24, 637. http://dx.doi.org/10.1007/s11224-012-0113-0

14. Dybal, J.; Makrlı'k, E.; Vanuura, P. Monatsh. Chem. 2010, 141, 15. http://dx.doi.org/10.1007/s00706-009-0217-4 
15. Zhu, R.; Janetzko, F.; Zhang, Y.; van Duin, A. C. T.; Goddard III, W. A.; Salahub, D. R. Theor. Chem. Account, 2008, 120, 479.

http://dx.doi.org/10.1007/s00214-008-0440-9

16. Denis, P. A.; Iribarne, F. Chem. Phys. 2014, 430, 1. http://dx.doi.org/10.1016/j.chemphys.2013.11.013

17. Wan, L.; Qi, D.; Zhang, Y. J. Mol. Graph. Model. 2011, 30, 15. http://dx.doi.org/10.1016/j.jmgm.2011.05.003

18. Adrian-Scotto, M.; Mallet, G.; Vasilescu, D. J. Mol. Struct. (Theochem) 2005, 728, 231. http://dx.doi.org/10.1016/j.theochem.2005.02.006

19. Khanmohammadi, H.; Keypour, H.; Salehei Fard, M.; Abnosi, M. H. J. Incl. Phenom. Macrocycl. Chem. 2009, 63, 97. http://dx.doi.org/10.1007/s10847-008-9495-4

20. Obijalska, E.; Kaszyński, P.; Jankowiak, A.; Young, V. C. Polyhedron, 2011, 30, 1339. http://dx.doi.org/10.1016/j.poly.2011.02.023

21. Rutkowska-Zbik, D.; Witko, M.; Fiedor, L. J. Mol. Model. 2013, 19, 4661. http://dx.doi.org/10.1007/s00894-012-1459-3

22. Buchachenko, A. L.; Shchegoleva, L. N.; Shchegoleva, N. N. Chem. Phys. Lett. 2009, 483, 77.

http://dx.doi.org/10.1016/j.cplett.2009.10.044

23. Doskocz, M.; Malinowska, B.; Lejczak, B.; Kafarski, P. J. Mol. Struct. 2009, 920, 103. http://dx.doi.org/10.1016/j.molstruc.2008.10.027

24. Doskocz, M.; Kubas, K.; Frąckowiak, A.; Gancarz, R. Polyhedron 2009, 28, 2201. http://dx.doi.org/10.1016/j.poly.2009.01.046

25. Kujawski, J.; Doskocz, M.; Popielarska, H.; Myka, A.; Drabińska, B.; Kruk, J.; Bernard, M. K. J. Mol. Struct. 2013, 1047, 292. http://dx.doi.org/10.1016/j.molstruc.2013.05.011

26. Kujawski, J.; Bernard, M. K.; Jodłowska, E.; Czaja, K.; Drabińska, B. J. Mol. Model. 2015, $5(105), 1$. http://dx.doi.org/10.1007/s00894-015-2643-z

27. Kujawski, J.; Czaja, K.; Ratajczak, R.; Jodłowska, E.; Chmielewski, M. K. Molecules 2015, 20(7), 11875.

http://dx.doi.org/10.3390/molecules200711875

28. Takahashi, M.; Suga, D. Synthesis 1998, 7, 986.

http://dx.doi.org/10.1055/s-1998-2096

29. Fielding, L. Prog. Nucl. Mag. Res. Sp. 2007, 51, 219. http://dx.doi.org/10.1016/j.pnmrs.2007.04.001

30. Vokácová, Z.; Trantírek, L.; Sychrovský, V. J. Phys. Chem. A 2010, 114, 10202. http://dx.doi.org/10.1021/jp102329t

31. Sychrovský, V.; Sochorová Vokáčová, Z.; Trantírek, L. J. Phys. Chem. A 2012, 116, 4144. http://dx.doi.org/10.1021/jp2110049 
32. Cheeseman, J. R.; Trucks, G. W.; Keith, T. A.; Frisch, M. J. J. Chem. Phys. 1996 104, 5497. http://dx.doi.org/10.1063/1.471789

33. Wolinski, K.; Hinton, J.F.; Pulay, P. J. Am. Chem. Soc. 1990, 112, 8251. http://dx.doi.org/10.1021/ja00179a005

34. Gaussian 09, Revision D.01, Frisch, M. J.; Trucks, G. W.; Schlegel, H. B.; Scuseria, G. E.; Robb, M. A.; Cheeseman, J. R.; Scalmani, G.; Barone, V.; Mennucci, B.; Petersson, G. A.; Nakatsuji, H.; Caricato, M.; Li, X.; Hratchian, H. P.; Izmaylov, A. F.; Bloino, J.; Zheng, G.; Sonnenberg, J. L.; Hada, M.; Ehara, M.; Toyota, K.; Fukuda, R.; Hasegawa, J.; Ishida, M.; Nakajima, T.; Honda, Y.; Kitao, O.; Nakai, H.; Vreven, T.; Montgomery, J. A., Jr.; Peralta, J. E.; Ogliaro, F.; Bearpark, M.; Heyd, J. J.; Brothers, E.; Kudin, K. N.; Staroverov, V. N.; Kobayashi, R.; Normand, J.; Raghavachari, K.; Rendell, A.; Burant, J. C.; Iyengar, S.

S.; Tomasi, J.; Cossi, M.; Rega, N.; Millam, J. M.; Klene, M.; Knox, J. E.; Cross, J. B.; Bakken, V.; Adamo, C.; Jaramillo, J.; Gomperts, R.; Stratmann, R. E.; Yazyev, O.; Austin, A. J.; Cammi, R.; Pomelli, C.; Ochterski, J. W.; Martin, R. L.; Morokuma, K.; Zakrzewski, V. G.; Voth, G. A.; Salvador, P.; Dannenberg, J. J.; Dapprich, S.; Daniels, A. D.; Farkas, Ö.; Foresman, J. B.; Ortiz, J. V.; Cioslowski, J.; Fox, D. J. Gaussian, Inc., Wallingford CT, 2009.

35. Simon, S.; Duran, M.; Dannerberg, J. J. J. Phys. Chem. A 1999, 1031640. http://dx.doi.org/10.1021/jp9842188

36. Wang, J.; Wolf, R. M.; Caldwell, J. W.; Kollman, P. A.; Case, D. A. J. Comput. Chem. 2004, 25, 1157. http://dx.doi.org/10.1002/jcc.20035

37. Jorgensen, W. L.; Chandrasekhar, J.; Madura, J. D.; Impey, R. W.; Klein, M. L. J. Chem. Phys. 1983, 79, 926.

http://dx.doi.org/10.1063/1.445869

38. Findeisen, M.; Brand, T.; Berger, S. Magn. Res. Chem. 2007, 45, 175.

http://dx.doi.org/10.1002/mrc.1941

39. Piotto, M.; Vourdonneau, M.; Elbayed, K.; Wieruszeski, J.-M.; Lippens, G. Magn. Res. Chem. 2006, 44, 943. http://dx.doi.org/10.1002/mrc.1884

40. Mąkosza, M.; Goliński, J.; Baran, J. J. Org. Chem. 1984, 49, 1488. http://dx.doi.org/10.1021/jo00183a003

41. Bernard, M. K.; Mąkosza, M.; Szafran, B.; Wrzeciono, U. Liebigs Ann. Chem. 1989, 545. http://dx.doi.org/10.1002/jlac.198919890196

42. Parr, R. G.; Yang, W. Density-Functional Theory of Atoms and Molecules, Oxford University Press: New York, 1994.

43. Becke, A. D. J. Chem. Phys. 1993, 98, 5648.

http://dx.doi.org/10.1063/1.464913 
44. Petersson, G. A.; Bennett, A.; Tensfeldt, T. G.; Al-Laham, M. A.; Shirley, W. A.; Mantzaris, J. J. Chem. Phys. 1988, 89, 2193.

http://dx.doi.org/10.1063/1.455064

45. Cammi, R.; Mennucci, B.; Tomasi, J. J. Phys. Chem. A 2000, 104, 5631. http://dx.doi.org/10.1021/jp0001561

46. Davidson, N. Statistical Mechanics, McGraw-Hill, New York, 1962.

47. Sychrovsky, V.; Grafenstein, J.; Cremer, D. J. Chem. Phys. 2000, 113, 3530. DOI: $10.1063 / 1.1286806$

48. Sychrovsky, V.; Sponer, J.; Trantirek, L.; Schneider, B. J. Am. Chem. Soc. 2006, 128, 6823. DOI: $10.1021 / \mathrm{ja} 0551180$

49. Barfield, M. J. Am. Chem. Soc. 2002, 124, 4158.

DOI: $10.1021 / \mathrm{ja} 012674 \mathrm{v}$

50. Pierens, G. K. J. Comput. Chem. 2014 35, 1388.

DOI: $10.1002 /$ jcc. 23638

51. ChemCraft. Available online: http://www.chemcraftprog.com (accessed on 20 May 2015)

52. van der Spoel, D.; Lindahl, E.; Hess, B.; Groenhof, G.; Mark, A. E.; Berendsen, H. J. C. J. Comput. Chem. 2005, 26, 1701. DOI: 10.1002/jcc.20291

53. Humphrey, W.; Dalke, A.; Schulten, K. J. Molec. Graph. 1996, 14, 33.

DOI: 10.1016/0263-7855(96)00018-5 